\title{
Seismic internal stability assessment of geosynthetic reinforced earth retaining wall in cohesive soil using limit analysis
}

\author{
Hicham Alhajj Chehade ${ }^{1,2}$, Daniel Dias ${ }^{3,4}$, Marwan Sadek $^{2}$, Fadi Hage Chehade ${ }^{2}$, Orianne \\ Jenck $^{1}$ \\ ${ }^{1}$ Univ. Grenoble Alpes, CNRS, Grenoble INP**, 3SR, F-38000 Grenoble, France \\ ${ }^{2}$ Lebanese University, Doctoral School of Sciences and Technologies, Beirut, Lebanon \\ ${ }^{3}$ Hefei University of Technology, School of Automotive and Transportation Engineering, Hefei, \\ China \\ ${ }^{4}$ Antea Group, Antony, France
}

\begin{abstract}
Assessment of internal seismic stability of geosynthetic reinforced cohesive soil retaining walls with likelihood for developing cracks in the failure mechanism is typically done with the limit equilibrium method. However, in this paper, the kinematic theorem of limit analysis combined with the discretization method are used to implement the crack formation in the collapse mechanism in the internal seismic assessment of geosynthetic reinforced soil retaining walls within the framework of the pseudo-static approach. The presence of the crack leads to an increase of the required reinforcement strength that prevent the failure of the structure.
\end{abstract}

\section{INTRODUCTION}

Reinforced soil retaining walls, by being both heavy and flexible, demonstrate its effectiveness performance even in seismically active areas [1]. This technique is now used more frequently than their conventional counterparts due to its cost effectiveness. Depending of the environment corrosion, inextensible metallic or extensible geosynthetics reinforcement are used in these structures.

In current deign recommendations, a cohesionless soil is used for the backfill. Nevertheless, for practical or/and economic reasons related to the availability of granular material, cohesive soils are used as backfill for reinforced earth retaining walls in many areas across the world and show good performances[2]. The use of a cohesionless soils leads to a possible crack formation in the backfill that reduce the structure stability, since their tensile strength is very limited [3], hence the importance of consideration of the crack-formation as part of the failure mechanism. The investigation of the seismic stability of reinforced soil retaining structures can be grouped into the numerical finite elements and finite differences 
methods, the experimental methods, the limit equilibrium methods and the limit analysis. Most analysis conducted in the literature have been carried to assess the influence of cracks on unreinforced slope stability considering a pre-existing crack through modification of geometry in limit equilibrium analysis[4]. More recently, the crack opening mechanism, requiring therefore energy during the crack formation process, is considered using the kinematic approach of limit analysis [5]. Abd and Utili [2017] first considered existing cracks referred as climate cracks, as well as tension crack formation as a part of the failure mechanism for geosynthetic reinforced slopes under static condition using the kinematic theorem of limit analysis.

A research investigation using the kinematic approach of limit analysis combined with the discretization method was carried out to assess the seismic stability of Geosynthetic reinforced earth retaining wall in cohesive soils. This paper presents an overview of the methodology used in the analysis concerning the assumptions of the kinematic theorem of limit analysis, the generation of the discretized failure mechanism and work calculations. The influence of cracks on the seismic stability of Geosynthetic reinforced soil retaining wall is then investigated.

\section{Methodology}

\subsection{Kinematic theorem of limit analysis of reinforced soil retaining wall stability}

Kinematic approach of limit analysis, based on the plasticity upper bound theory, is based on the work rate balance equation for any kinematically admissible velocity field. Applicability of the theorem requires an ideally rigid, perfectly plastic behavior of the soil mass according to an associated normality rule based on the Coulomb yield criterion. Resistance to shear, bending and compression of the geosynthetic reinforcement are negligible. Pore water pressure and liquefaction potential are not considered.

A rotational two-dimensional toe log-spiral mechanism is assumed since it was found in the previous work [3] that it is the most critical for this type of structures. In addition, using the limit analysis method, Gao et al. [6] proved that there is no three-dimensional analysis that can improve the two-dimensional analysis results.

\subsection{Generation of the discretized failure mechanism}

The spatial discretization technique coupled with limit analysis method proposed by Mollon et al. [7] to assess the tunnel face stability is extended here to generate the failure mechanism with crack of the reinforced earth retaining wall as shown in fig. 1. The use of this technique allows to overcome the main imitation of the traditional kinematic approach. It allows to represent the seismic forces by the pseudo-dynamic approach and the consideration of heterogeneous or multilayered soil.

The region of soil $\mathrm{ABCD}$, separated from the soil at rest by the sliding surface formed by a log-spiral part $\mathrm{BC}$ and the vertical crack $\mathrm{CD}$, is assumed to rotate rigidly around the center $\mathrm{O}$ with an angular velocity $\Omega$. The failure mechanism is determined by the mechanism parameters $r_{B}, \theta_{B}$ and $\xi$, where $r_{B}$ is the length of $O B, \theta_{B}$ is the angle between the $y$ axis direction and the line $O B$ and $\xi$ is a parameter to define the crack depth (Fig.1). Starting at the wall toe, the points $B_{j}$ are successively generated until reaching the ground surface in a manner that the kinematically admissibility condition is satisfied and therefore, the failure surface meet the velocity vector with an angle equal to the soil friction angle. The angle 
between two consecutives radial lines denoted $\chi_{j}$ is noted $\delta \theta$, which defines the accuracy of the failure mechanism. The smaller this angle, the more accurate the failure mechanism. Based on the established coordinate system with A being the origin, the coordinates of all points are determined using the geometrical and trigonometrical relations [8].

\subsection{Maximum depth of a vertical crack in soil}

The depth of vertical crack in the soil is limited by the stability requirement of the crack boundaries [3]. The expression of the rigorous upper bound to the maximum critical depth in a dry backfill is adopted here. The closed-form solution according to many researchers [5] is as follow:

$$
h=\frac{3.83 c}{\gamma} \tan \left(\frac{\pi}{4}+\frac{\varphi}{2}\right)
$$

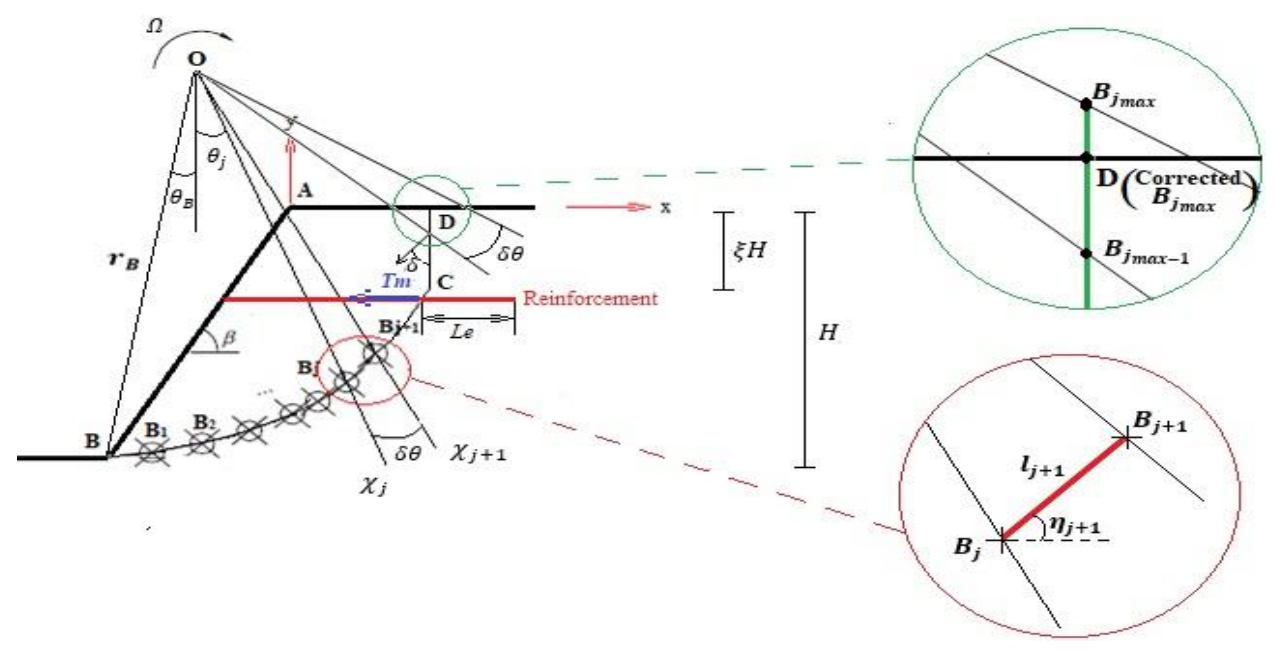

Fig.1. Discretization technique for the failure mechanism of a reinforced soil retaining wall with cracks

\section{Kinematic stability analysis with pseudo static approach}

To represent the ground shaking, the pseudo static approach is used. Then, the seismic action is represented by horizontal and vertical pseudo-static forces ( $k_{h} g$ and $k_{v} g$ respectively). Despite its simplicity, the pseudo static approach presents the inconvenient of not considering the time and spatial variation of the ground shaking.

The kinematic approach uses the energy balance, to determine the lower bound of the required reinforcement strength expressed as :

$$
k_{t}=n_{r} T_{m} / H
$$

where $T_{m}$ is the tensile strength of a single reinforcement layer and $n_{r}$ is the number of reinforcement layers.

In order to compute the external work done by the soil weight and inertia forces, the trapezoidal element $B_{j}^{\prime} B_{j+1}^{\prime} B_{j+1} B_{j}$ as shown in Fig. 2 is considered. The computation of external work rate is done by the summation of these elementary work rate. The energy dissipation takes place in the soil masses and along the reinforcement. The combined failure 
of reinforcement (tension and pullout) is considered (Refer to Alhajj Chehade et al. (2019) for the calculation details).

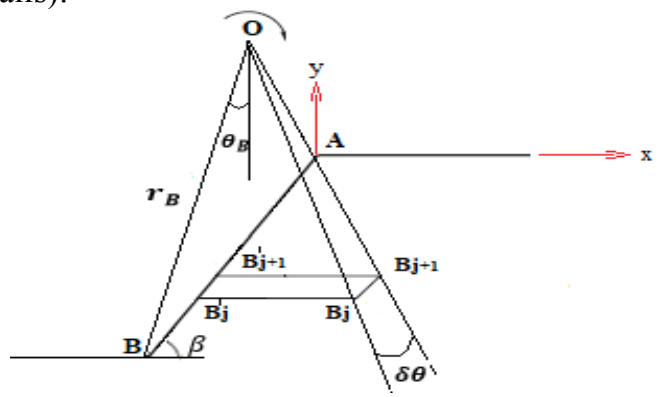

Fig. 2. Elementary trapezoidal surface $B_{j}^{\prime} B_{j+1}^{\prime} B_{j+1} B_{j}$ for calculation of work rate

According to the upper bound theorem, the energy balance equation provides the objective function to be optimized in order to determine the required reinforcement strength. Three variables are considered in the optimization process using the MATLAB genetic algorithm toolbox, namely $\left[r_{B}, \theta_{B}, \xi\right]$.

\section{Influence of the cracks on the seismic stability of geosynthetic reinforced soil retaining walls}

To present the importance of considering cracks in the analysis, the proposed method that combines the kinematic theorem of limit analysis and the discretization method is used to determine the required reinforcement strength to maintain the structure stability considering or not the crack formation. Two reinforced soil wall inclinations are considered: $0^{\circ}$ and $15^{\circ}$, corresponding respectively to $\beta=90^{\circ}, \beta=75^{\circ}$. The following parameters are considered: $H=7 \mathrm{~m}, \gamma=18 \mathrm{kN} / \mathrm{m}^{3}, c=10 \mathrm{kPa}, \varphi=25^{\circ}, \delta \theta=0.01^{\circ}, \lambda=0.5, L_{r}=H, S_{V}=0.7 \mathrm{~m}, f_{0}^{*}=1.2$, $f_{1}^{*}=0.6$.

where $\lambda=k_{v} / k_{h}, L_{r}$ is the reinforcement length, $S_{V}$ is the vertical reinforcement spacing, $f_{0}^{*}$ and $f_{1}^{*}$ are the initial and the minimum apparent friction coefficients at the soil/strip interface.

Fig. 3 shows the required reinforcement strength for different values of horizontal seismic coefficients. Two crack cases are considered: No-crack and crack-formation as a part of the failure mechanism. It shows that the required reinforcement is greater when considering the crack in the failure mechanism. This difference is more significant with the increase in the values of seismic coefficient.

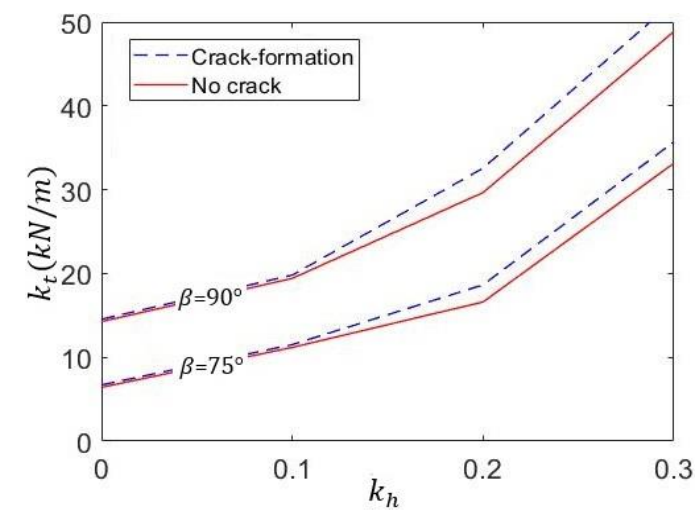

Fig.3. Reinforcement strength against seismic coefficient 
Eurocode 8 among other references (NCHRP [9]; FHWA [10]), overlooks the effects of vertical acceleration for the non-gravity retaining structure. They consider that the vertical and the horizontal accelerations will be out of phase, and consequently, the alternatingly positive and negative impacts of the vertical acceleration on earth pressures, on average, can be assumed to be zero [11].

To assess the reliability of assumption defined by the Eurocode 8 and other codes, Fig. 4 shows the effect of the vertical acceleration $k_{v}$ on the required normalized reinforcement strength for a reinforced cohesive soil retaining wall considering the crack formation. A positive value of $k_{v}$ corresponds to a downward vertical seismic force, whereas a negative value corresponds to an upward one. The downward vertical seismic force is unfavorable for the reinforced earth retaining wall, whereas, the upward vertical seismic force leads to a decrease in the required normalized reinforcement strength. The larger the amplitude of the downward vertical acceleration, the higher the geosynthetic reinforcement force required for structure stability. The required reinforcement strength increases uniformly with the increase of the horizontal seismic coefficient and the tension failure is the only failure mode observed in the reinforcements. Beyond a specific value of $k_{h}$, the rate of increase is more pronounced. This due to the pullout failure occurred in some reinforcement layers.
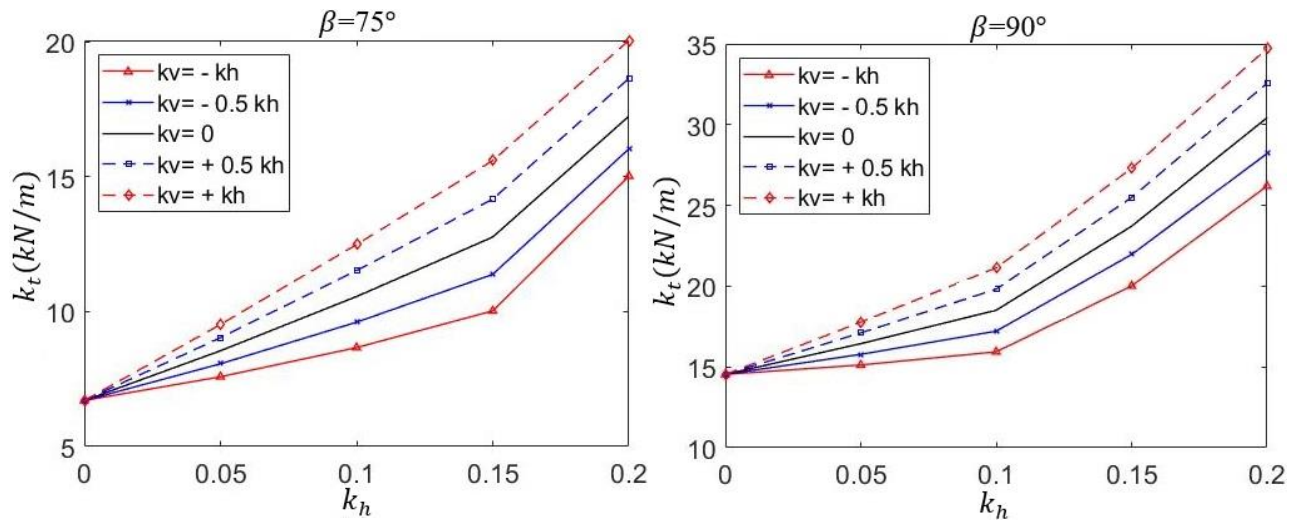

Fig.4. Influence of the vertical seismic coefficient

\section{Conclusion}

In this study, the kinematic approach of limit analysis combined with the discretization method appear to be an effective way to assess the seismic internal stability of geosynthetic reinforced soil retaining walls with the consideration of the crack formation. A pseudo-static approach is used to represent the seismic loading. A rotational collapse mechanism is considered to illustrate the application of limit analysis to these structures.

The consideration of the crack formation in the collapse mechanism is found to have a negative effect on the stability of reinforced walls requiring therefore greater amount of reinforcement strength hence the importance of consideration of crack formation in the stability assessment.

The effects of the vertical seismic coefficient $k_{h}$ on the required reinforcement strength is evident. A downward vertical acceleration requires greater reinforcement strength, whereas an upward vertical acceleration has an opposite effect.

The use of this technique allows to represent the seismic forces by the pseudo-dynamic approach and the consideration of heterogeneous or multilayered soil in future works which overcome main limitations of the traditional limit analysis method. 


\section{References}

1. J. Koseki, R.J. Bathurst, E. Guler, J.Kuwano, M. Maugeri, 8th Int Conf Geosynth, 28 (2006)

2. M. Riccio, M. Ehrlich, D. Dias, Geotext Geomembranes, 42, 12 (2014)

3. A.H. Abd, S. Utili, Geotext Geomembranes, 45,15 (2017)

4. R. Baker, D. Leshchinsky, Int J Numer Anal Methods Geomech, 27, 22 (2003)

5. R.L. Michalowski, Can Geotech J, 50, 11 (2013)

6. Y. Gao, S. Yang, F. Zhang, B. Leshchinsky, Geotext Geomembranes 44, 10 (2016)

7. G. Mollon, D. Dias, A-H. Soubra, Int J Numer Anal Methods Geomech, 35, 28 (2011)

8. H. Alhajj Chehade, D. Dias, M. Sadek, O. Jenck, F. Hage Chehade, Acta Geotech (to be published)

9. NCHRP (National Cooperative Highway Program), NCHRP Project 12-70, NCHRP Report 611, Transportation Research Board, Washington D.C. (2008)

10. FHWA (Federal Highway Administration), Geotechnical Engineering Circular No.3, FHWA - NHI-11-032, U.S. Department of Transportation - Federal Highway Administration, Washington D.C. (2011)

11. G. Pereira, P. De La Vernee, P. Schmitt, 16 TH European Conference on Earthquake Thessaloniki Engineering, 14 (2018) 